\title{
Re-irradiation alternatives for recurrent high-grade glioma (Review)
}

\author{
YUANLI DONG ${ }^{1,2}$, CHENGRUI FU ${ }^{1}$, HUI GUAN ${ }^{1,2}$, TIANYI ZHANG ${ }^{1}$, \\ ZICHENG ZHANG ${ }^{1}$, TAO ZHOU ${ }^{1}$ and BAOSHENG LI ${ }^{1}$ \\ ${ }^{1}$ Sixth Department of Radiation Oncology, Shandong Cancer Hospital, Jinan, Shandong 250117; \\ ${ }^{2}$ School of Medicine and Life Sciences, University of Jinan-Shandong Academy \\ of Medical Sciences, Jinan, Shandong 250014, P.R. China \\ Received February 8, 2015; Accepted March 1, 2016
}

DOI: $10.3892 / 01.2016 .4926$

\begin{abstract}
Despite advances in the fields of surgery, chemotherapy and radiotherapy, the prognosis for high-grade glioma (HGG) remains unsatisfactory. The majority of HGG patients experience disease recurrence. To date, no standard treatments have been established for recurrent HGG. Repeat surgery and chemotherapy demonstrate moderate efficacy. As recurrent lesions are usually located within the previously irradiated field, a second course of irradiation was once considered controversial, as it was considered to exhibit unsatisfactory efficacy and radiation-related toxicities. However, an increasing number of studies have indicated that re-irradiation may present an efficacious treatment for recurrent HGG. Re-irradiation may be delivered via conventionally fractionated stereotactic radiotherapy, hypofractionated stereotactic radiation therapy, stereotactic radiosurgery and brachytherapy techniques. In the present review, the current literature regarding re-irradiation treatment for recurrent $\mathrm{HGG}$ is summarized with regard to survival outcome and side effects.
\end{abstract}

\section{Contents}

1. Introduction

2. Treatment alternatives for re-irradiation

3. Conclusion

\section{Introduction}

In the United States, high-grade glioma (HGG) [World Health Organization (WHO) grade III-IV] (1) accounts for

Correspondence to: Miss. Baosheng Li, Sixth Department of Radiation Oncology, Shandong Cancer Hospital, 440 Jiyan Road, Jinan, Shandong 250117, P.R. China

E-mail: sdchbaoshengli@126.com

Key words: high-grade glioma, re-irradiation, toxicity
$>60 \%$ of primary central nervous system tumor in adults, accounting for $>60 \%$ of all brain tumors (2). Following the development of temozolomide (TMZ), which is administered concurrently or as an adjuvant after radiotherapy, the median survival time of glioblastoma patients has improved from 12.1 (no TMZ treatment) to 14.6 months (with TMZ treatment) (3). However, recurrence remains a problem in the majority of cases due to the infiltrative and radioresistant nature of the tumor cells (4). External beam re-irradiation in HGG was first reported in 1996 (5). However, severe toxicity was observed and post-overall survival (OS) (median OS after re-irradiation) and post-progression free survival (PFS) (median PFS after re-irradiation) times (2.8 and 1.4 months, respectively) were unsatisfactory (6-9). Following the development of irradiation techniques, re-irradiation may be delivered through conventionally fractionated stereotactic radiotherapy, hypofractionated stereotactic radiation therapy, stereotactic radiosurgery and brachytherapy. Re-irradiation has been demonstrated to exhibit moderate therapeutic efficacy with acceptable toxicities. Fokas et al (10) reported no significant difference between post-OS time following re-irradiation ( 9 months) and re-surgery ( 9 months) $(\mathrm{P}>0.05)$. Furthermore, a retrospective cohort study of 111 patients with recurrent glioblastoma multiforme compared survival between re-irradiation, resection and chemotherapy (11). The median survival after treatment was 37,30 and 26 weeks, respectively, suggesting that re-irradiation serves as an effective salvage therapy. Furthermore, Archavlis et al (11) revealed that re-irradiation significantly improved survival time compared with re-operation and chemotherapy alone (11). Currently, re-irradiation alternatives for recurrent HGG vary among medical centers. Conventionally fractionated stereotactic radiotherapy is used for the majority of cases, as this technique causes the least damage to normal tissues $(6,12)$. As a result of increased understanding with regard to radiation biology, hypofractionated stereotactic radiation therapy, which delivers a higher dose than conventionally fractionated stereotactic radiotherapy, may also be administered $(13,14)$. Stereotactic radiosurgery, commonly used to deliver high doses in a single fraction, is particularly advantageous for the treatment of smaller lesions $(15,16)$. In addition, brachytherapy, which is an invasive radiotherapy, presents an additional treatment 
method for recurrent HGG $(17,18)$. Novel techniques such as pulsed reduced dose rate radiotherapy (19) and boron neutron capture therapy (20) have also been investigated. However, data regarding survival and treatment-related toxicities remain inconsistent $(6,12-20)$. Thus, in the present review, an overview of the treatment alternatives for re-irradiation is provided with regard to survival outcomes and side effects.

\section{Treatment alternatives for re-irradiation}

Conventionally fractionated stereotactic radiotherapy (FSRT). FSRT is defined as radiotherapy delivered at a dose of $<3$ Gy per fraction, with the aim of minimizing normal tissue toxicity. A number of previous studies have reported the use of FSRT (Table I). In these studies, the post-OS time ranged between 8 and 16 months, and the post-PFS time ranged between 5 and 8 months $(6,12,21-27)$. The highest post-OS time observed for WHO grade III glioma was 16 months $(22,23)$. Regarding WHO grade IV glioma, when a second course of irradiation was combined with thermotherapy, the highest post-OS time was 13.4 months (24). Furthermore, Cho et al (21) reported that post-OS time was 12 months for individuals in a relatively poor condition [median Karnofsky performance status (KPS) score, 60] (28) who could not tolerate aggressive treatment, indicating that FSRT may present a useful treatment in this subset of patients. Bevacizumab, a humanized monoclonal antibody that targets vascular endothelial growth factor (VEGF), is a feasible anti-angiogenic drug that is often used in the treatment of glioma (29). Compared with FSRT alone, FSRT in combination with bevacizumab significantly increases post-OS time (5.7 vs. 8.6 months, respectively) and post-PFS time (2.5 vs. 5.6 months, respectively) (27). In the present review, to compare the incidence of severe toxicity among previous studies, severe toxicity was defined as the following: The occurrence of $\geq$ grade 3 adverse events according to each study, clinical or pathological radionecrosis, complications requiring surgery, and the occurrence of meningitis or wound infection.

Overall, the severe toxicity rate of FSRT ranged between 0 and $16 \%$. In a study with a dose scheme of 41.6/2.66 Gy and the largest planning target volume reported to date, the side effects were well tolerated with a toxicity rate of $7.10 \%$ (26). No significant increase in toxicity was identified in patients receiving FSRT treatment combined with TMZ or bevacizumab.

FSRT treatment aims to minimize damage to normal tissues by fractionation, which is most beneficial in patients with large lesions or lesions adjacent to eloquent structures. Furthermore, the severe toxicity rate for FSRT was relatively low when compared with other re-irradiation alternatives, which are also discussed in this review.

Hypofractionated stereotactic radiotherapy (HSRT). HSRT, usually administered at a fractional dose of $>3$ Gy, takes advantage of a higher fractional dose of stereotactic radiosurgery (SRS), while maintaining the merits of FSRT in the protection of normal brain tissue. As shown in Table II, HSRT has been reported to be effective in recurrent $\mathrm{HGG}$, with a post-OS time ranging from 7.4-16.5 months and a post-PFS time ranging from $5.8-15$ months $(7-10,13,14,30-38)$. It was demonstrated that patients treated with HSRT exhibited the same post-OS time of 9 months as patients treated with repeat surgery $(\mathrm{P}>0.05)(10)$. In a previous study by Patel et al (34), patients with smaller tumor volumes (median, $10.4 \mathrm{ml}$ ) were treated with SRS, whereas patients with larger tumor volumes (median, $51.1 \mathrm{ml}$ ) were treated with HSRT. The post-OS time for HSRT was 7.4 months compared with 8.5 months for SRS $(\mathrm{P}=0.81)(34)$. These results revealed that when indications were carefully considered, no significant differences in survival time were identified between patients treated with HSRT or re-operation and SRS. With regard to total dose of HSRT, Vordermark et al (13) reported that post-OS time was longer in patients administered a total dose of $30 \mathrm{~Gy}$ when compared with those treated with a total dose of $<30$ Gy $(\mathrm{P}=0.051)$. Fogh et al (35) observed that a total dose of $\geq 35$ Gy resulted in an improved post-OS time. However, patients who received a dose of $>40$ Gy exhibited 6.4 times the risk of damage compared with those who received $\leq 40$ Gy (30). Thus, a total dose of 30-35 Gy is the dose applied by the majority of radiation oncologists. A recent study of 147 patients treated with HSRT reported a post-OS time of 11 months for grade IV tumors (35), which is longer than that reported by Vordermark et al (13) and Patel et al (34). However, conservative dose may partially account for this survival difference, as one-third of patients only received 20 Gy in the study by Vordermark et al (13).

Another previous study indicated that TMZ may act as a radiation sensitizer (39). Thus, TMZ in combination with HSRT has also been investigated. Grosu et al (31) reported that HSRT treatment in combination with TMZ significantly increased survival time compared with HSRT treatment alone (11 vs. 6 months; $\mathrm{P}=0.04$ ). However, controversy remains over whether TMZ or bevacizumab increase the efficacy of HSRT. Fogh et al (35) hypothesized that bevacizumab confers no survival advantage when combined with irradiation, however, only 4/147 patients received bevacizumab in this study. Using a treatment scheme modeled around the study by Voredermark et al (13), Gutin et al (33) investigated combined HSRT and bevacizumab treatment and found that survival time was longer in patients receiving combined treatment when compared with the results for HSRT alone from the study by Vordermark et al (13), particularly when larger tumor volumes were considered: Post-OS, 16.5 vs. 15.4 months (WHO grade III) and 12.5 vs. 7.9 months (WHO grade IV) (33).

Generally, combined treatment with HSRT and bevacizumab or TMZ has demonstrated an increased survival time of 12.2-16.5 months. In addition to bevacizumab, other inhibitors of the VEGF pathway, such as sorafenib and sunitinib, have been investigated for the treatment of recurrent HGG. In 2012, a phase I study of sorafenib combined with HSRT achieved a median post-OS time of 24 months, which is the longest post-OS time reported to date (40). In 2014, a pilot study of HSRT and sunitinib reported a post-OS time of 12.7 months, which is the longest post-OS time reported for recurrent glioblastoma multiforme (GBM) (38). However, further study is required to validate these results.

The severe toxicity rate for HSRT ranges between 0 and $60 \%$. The highest toxicity rate was observed in a study by Voynov et al (7), however, this may have been due to the small sample size of only 10 patients. Although combined 


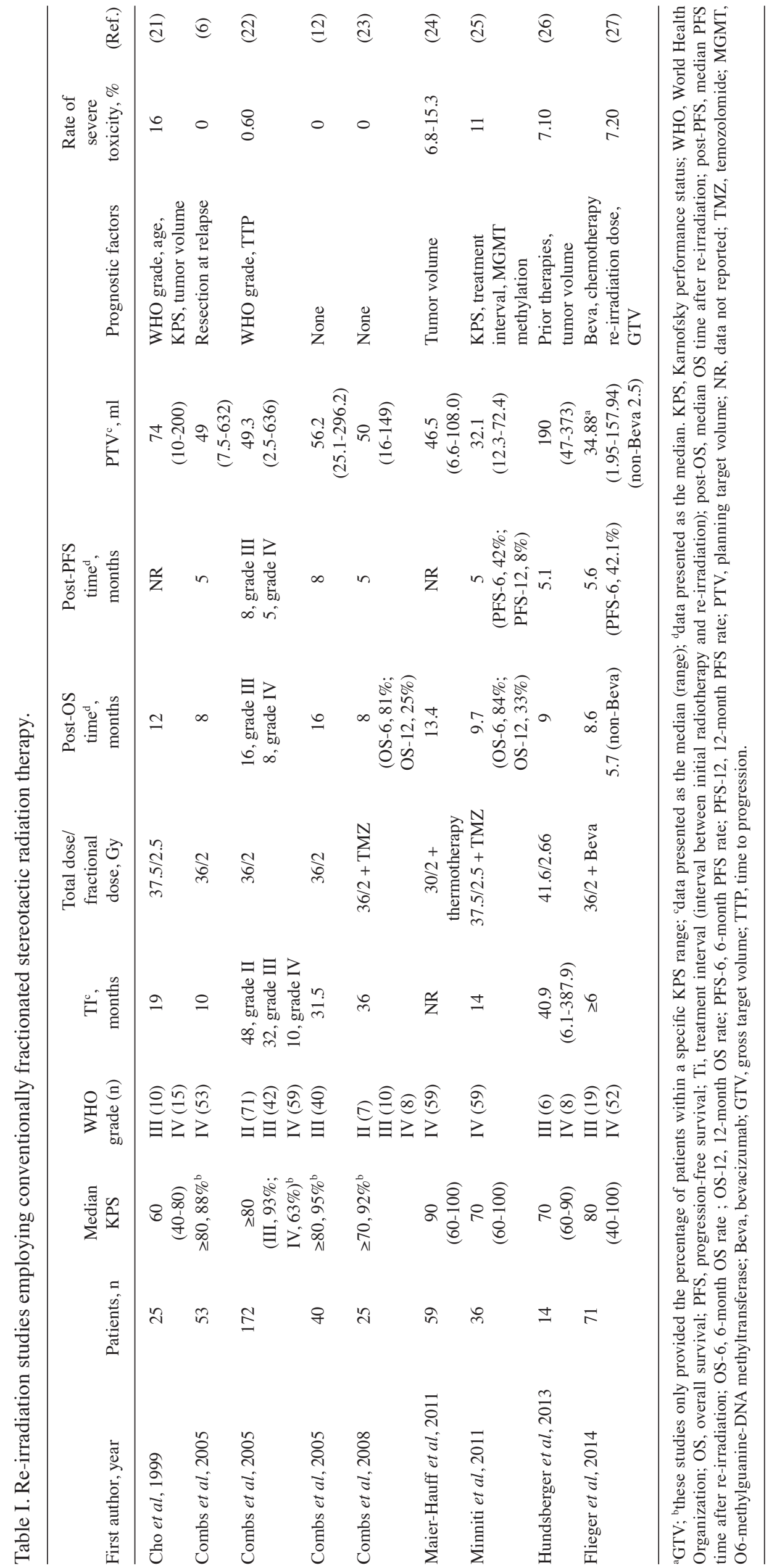




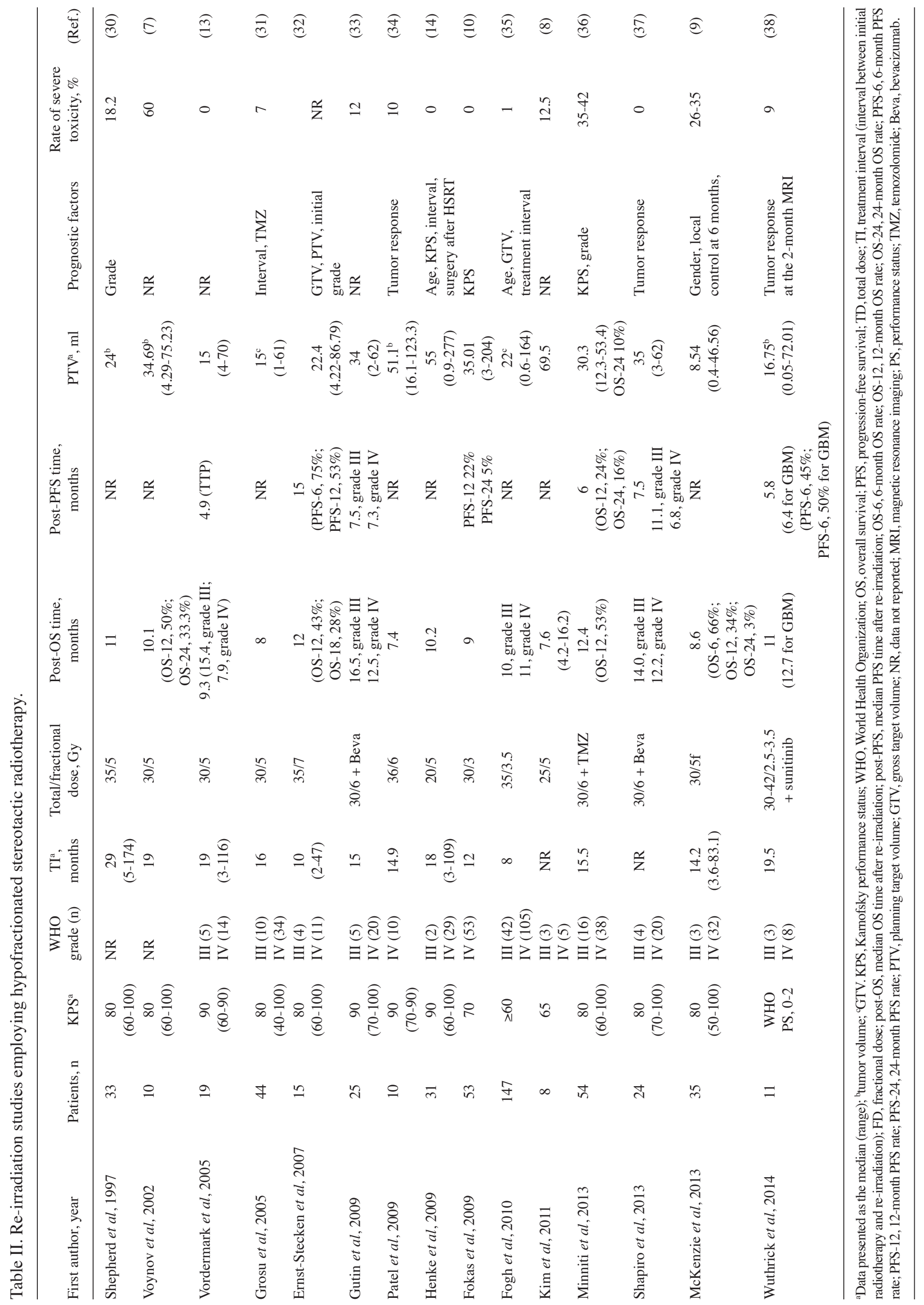




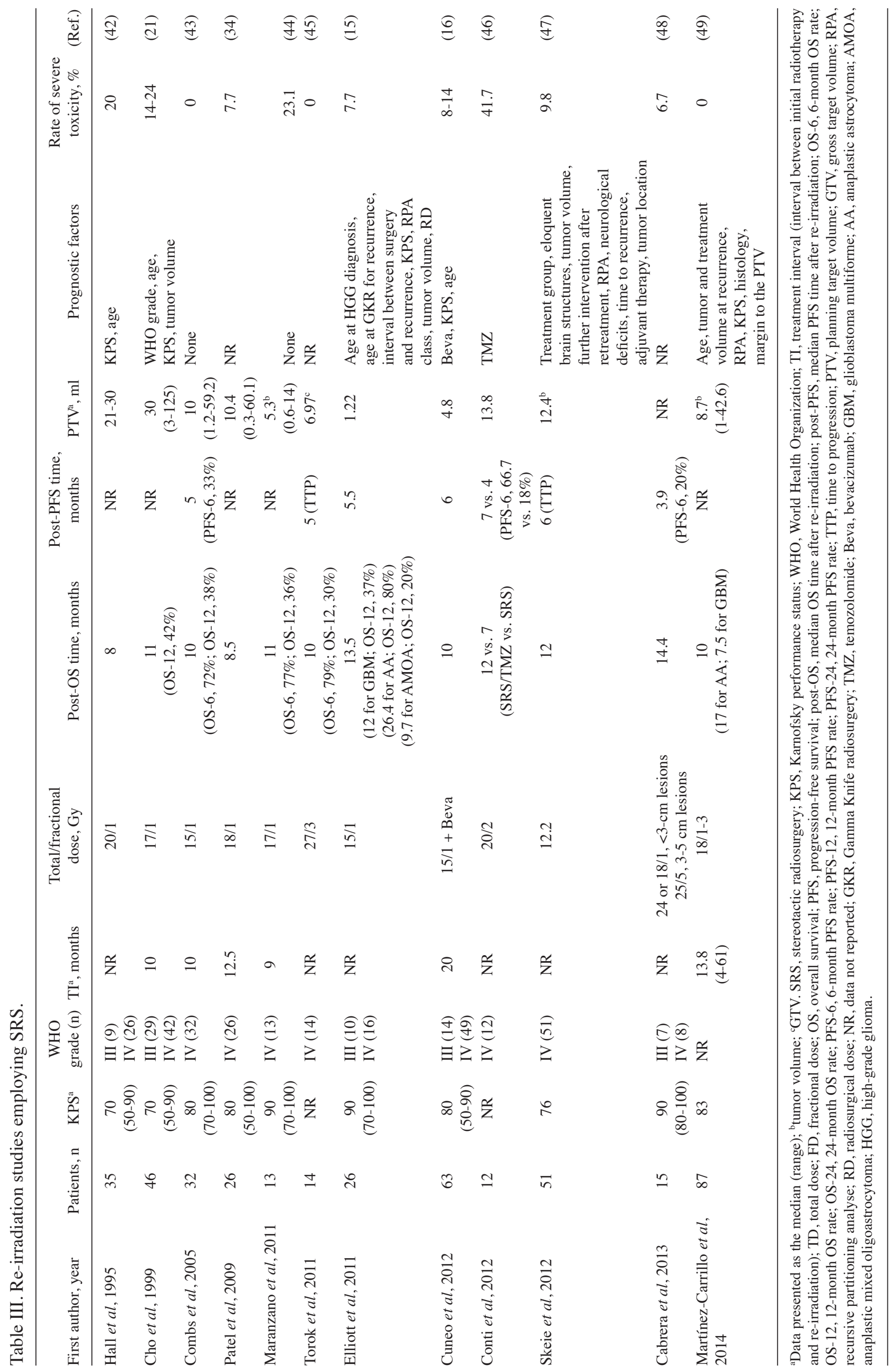


treatment with HSRT and TMZ increased the severe toxicity rate to $35-42 \%$, grade 3 neurological deterioration attributable to radiation-induced necrosis was managed successfully with high-dose dexamethasone and/or surgery (36). In contrast to TMZ, bevacizumab combined with HSRT achieved a relatively low toxicity rate of $0-12 \%(33,37)$. We hypothesize that the anti-angiogenic properties of bevacizumab may protect against the potential toxicity of dose escalation.

Although the severe toxicity rate for HSRT is higher than that of FSRT, HSRT remains well tolerated and fewer treatment fractions are required, reducing overall treatment time, which is particularly important for terminally ill patients. Notably, in the literature, HSRT combined with bevacizumab resulted in less toxicity when compared with HSRT combined with TMZ.

SRS. SRS is usually performed for relatively small lesions (maximal diameter, $<4 \mathrm{~cm}$ ) as high doses may be delivered in a single fraction with a lower incidence of treatment-associated morbidity (41). As shown in Table III, previous studies have demonstrated that SRS is beneficial for the management of recurrent glioma. Patients treated with SRS exhibited post-OS times ranging from 7-14.4 months, post-PFS times ranging from 3.9-6 months and a median time-to-progression (TTP) ranging from $4-6$ months $(12,15,16,34,42-49)$. In a previous study by Skeie et al (47), a total of 32 patients underwent SRS, 26 patients underwent repeat surgery and 19 patients were treated with both procedures. The results revealed that when compared with patients undergoing repeat surgery, the patients treated with SRS demonstrated an increased post-OS time (6 vs. 12 months; $\mathrm{P}=0.001$ ) and an increased post-TTP time ( 2 vs. 6 months; $\mathrm{P}=0.009)$ (47). A higher rate of late complications was also previously observed in patients treated with SRS compared with FSRT (30 vs. 8\%; P<0.05), however, no difference in survival time was identified between the treatments (12). The longest survival time of 14.4 months was reported by Cabrera et al (48). In this study, $50 \%$ of patients exhibited grade III tumors and received combined SRS and bevacizumab treatment, which may account for this result (48). To assess the efficacy of SRS and adjuvant bevacizumab, Cuneo et al (16) enrolled 63 patients and reported that for recurrent grade IV HGG patients, SRS combined with bevacizumab significantly increased the post-OS time (11.2 vs. 3.9 months), post-PFS time (5.2 vs. 2.1 months) and the 12 -month survival rate (50 vs. $22 \%$ ) when compared with SRS treatment alone (16). Similar findings were reported in the study by Conti et al (46), which demonstrated that the median survival time for patients undergoing SRS/TMZ was longer than that for those treated with SRS alone (12 vs. 7 months; $\mathrm{P}<0.01)$. Elliott et al (15) reported post-OS times of 12.9, 26.4 and 9.7 months for GBM, anaplastic astrocytoma and anaplastic mixed oligoastrocytoma patients, respectively, which were longer than the post-OS times exhibited by patients treated with FSRT or HSRT. However, the median lesion volume in this study was $1.22 \mathrm{ml}$, indicating that SRS may only benefit patients exhibiting smaller tumor volumes.

Overall, the severe toxicity rate for SRS ranges between 0 and $41.7 \%$. Following a literature review, Mayer and Sminia (50) concluded that radiation-induced normal brain tissue necrosis occurs at a biologically effective dose of $>200$ Gy and a normalized total dose $\left(\right.$ NTD $_{\text {cumulative }}$ ) of
$>100$ Gy (50). This conclusion may explain the severe toxicity rate of $23 \%$ reported in the study by Maranzano et al (44), in which 3 patients who exhibited brain radionecrosis were all treated with a $\mathrm{NTD}_{\text {cumulative }}$ dose of $>120 \mathrm{~Gy}$. Notably, the highest toxicity rates were associated with TMZ (46). By contrast, bevacizumab combined with SRS has been shown to result in fewer complications, with a severe toxicity rate ranging between 6.7 and 14\% (16,48).

The aforementioned studies indicate that SRS is beneficial for certain individuals with focal and small lesions. In comparison with HSRT, SRS treatment combined with bevacizumab resulted in less adverse reactions when compared with TMZ. The results also indicate that $\mathrm{NTD}_{\text {cumulative }}$ doses should not exceed $100 \mathrm{~Gy}$, to prevent radionecrosis.

Brachytherapy (BT). BT is an invasive form of radiotherapy in which radioactive seeds containing radioisotopes, such as iodine-125 $\left({ }^{125} \mathrm{I}\right)$ and iridium-192 $\left({ }^{192} \mathrm{Ir}\right)$, are placed in tumor sites, permanently or temporarily, during surgery (51). The radioisotope emits $\gamma$-rays that suppress tumor cells (51). The major advantage of BT is that it allows the delivery of a higher dose of radiation to the tumor volume, however, infection and hemorrhage are common (51). As shown in Table IV, the post-OS time following BT ranges between 32 and 71.6 weeks, and PFS ranges between 23.6 and 32 weeks $(11,17,18,52-58)$. Archavlis et al (11) reported that BT treatment resulted in significantly longer survival times (37 weeks) when compared with re-resection (30 weeks) or TMZ (26 weeks) alone, with less complications (11). Due to differences in total dose, dose rate, methods of placement and source activity, it is difficult to compare survival data directly among various studies. A number of studies have attempted to establish the appropriate total dose for BT. Regarding a low dose rate, Chan et al (54) found that patients who received doses of $<50 \mathrm{~Gy},>50 \mathrm{~Gy}$ and $<60 \mathrm{~Gy}$, or $>60 \mathrm{~Gy}$ exhibited no significant differences in survival after retreatment. Regarding a high dose rate, Tselis et al (56) treated 84 patients with computed tomography-guided interstitial ${ }^{192} \mathrm{Ir}$ high dose rate BT for recurrent cerebral GBM. The results demonstrated that patients who received total doses of 30,40 or 50 Gy exhibited no significant differences in post-OS times. Thus, these results suggest that total dose does not affect survival time after re-irradiation. According to the literature, recurrent GBM patients treated with high and low dose rate radiotherapy experienced survival times of 32-37 and 32-69 weeks, respectively. These results indicate that low dose rate radiotherapy results in increased survival times when compared with high dose rate radiotherapy, which could possibly be attributed to the low dose rate characteristic of synchronizing tumor cells to the radiosensitive $\mathrm{G}_{2}-\mathrm{M}$ phase (59). However, the optimal dose rate remains controversial. Koot et al (60) investigated BT treatment at various dose rates in patients with primary glioblastoma and concluded that dose rate did not affect survival time. In another study, BT treatment combined with carmustine wafers for the treatment of recurrent GBM resulted in the longest survival time of 69 weeks; however, the rate of severe toxicity was $35.3 \%$ (18). Despite a severe toxicity rate of 35\% in 17 patients, Archavlis et al (61) reported only a single case of radionecrosis in a patient with a relatively large tumor volume of $38.1 \mathrm{ml}$ (61). The study attributed the one case of radionecrosis to the 


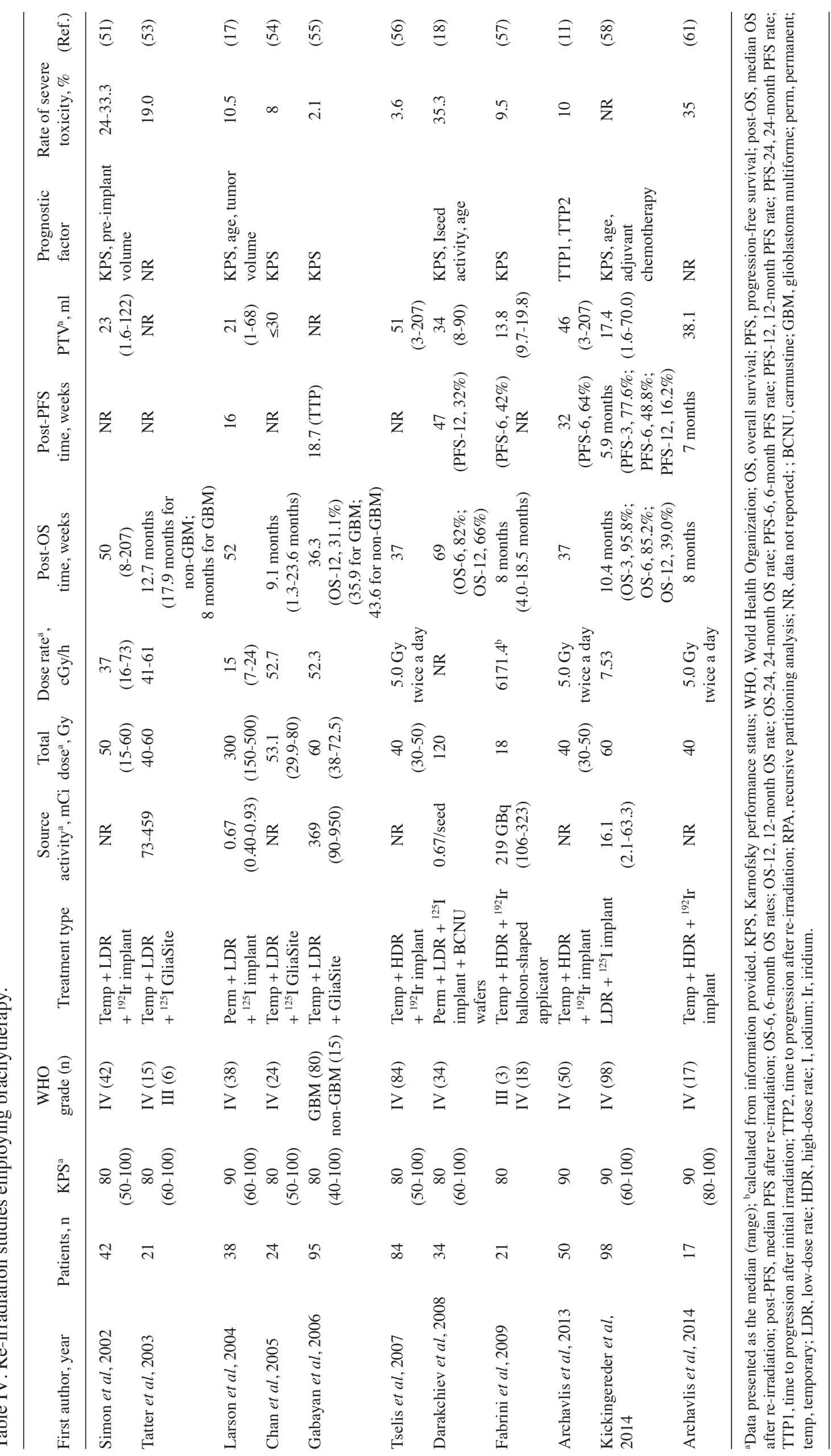


requirement for better fixation of the radioactive seeds, which would limit the radioisotopes from migrating. Discrete seed implants produce an inhomogeneous distribution of radiation dose, which is associated with radiation necrosis. This rationale also accounted for the lack of toxicity greater or equal to grade 3 in another study with a tumor volume of $46 \mathrm{ml}$ (11). Treatment using GliaSite BT (Gliasite, Cytic Surgical Products, Palo Alto, CA, USA), a single spherical source of low dose rate radiation, may achieve lower toxicity $(54,55)$. This technique utilizes an inflatable balloon that fits the resection cavity, contributing to a more uniform dose. KPS is the most common prognostic factor used in the literature, possibly due to the invasiveness of BT. Chan et al (54) reported that the median survival times for patients with KPS scores of $>70$ and $<70$ were 9.3 and 3.1 months, respectively. Furthermore, Gabayan et al (55) demonstrated that the median survival time was 45.3 weeks for patients with a KPS score of $\geq 90$ compared with 34.9 weeks for patients with a KPS score $<90$.

Overall, BT may present a promising treatment, particularly in individuals in a better condition (i.e., with a higher KPS score). The use of TMZ and bevacizumab in combination with BT has not been investigated, however, combined carmustine and BT treatment has been shown to result in severe toxicity. Improved methods of seed fixation may prevent radionecrosis, while total dose and dose rate remain controversial. Further study is required to investigate these factors.

Novel techniques. Pulsed reduced dose rate radiotherapy (PRDR) employs a dose rate of $6 \mathrm{cGy} / \mathrm{min}$, which allows for increased normal tissue repair. The technique was first reported by Cannon et al (19) in 2007 for the treatment of GBM. The total dose delivered to the tumor bed by PRDR was $104 \mathrm{~Gy}$, and no radionecrosis was identified. Notably, the patient exhibited a radiographic response and clinical improvement. Adkison et al (62) conducted a study using a larger patient cohort, which included 103 patients with recurrent HGG. The median PRDR retreatment dose was 50 Gy, delivered in 1.8 to $2.0-\mathrm{Gy}$ fractions at a dose rate of $0.0667 \mathrm{~Gy} / \mathrm{min}$. The post-OS times were 5.6 and 5.1 months for grade III and IV tumors, respectively. PRDR with cumulative doses of $>100$ Gy were also well tolerated. Notably, the mean treatment volume was $403.5 \pm 189.4 \mathrm{~cm}^{3}$, which is the largest volume reported to date. In the study, only $16 \%$ of patients were treated with PRDR at first relapse, indicating its potential use as a first-line salvage treatment. Brain autopsy revealed evident necrosis in $26.7 \%(4 / 15)$ patients (62).

Boron neutron capture therapy (BNCT) utilizes boron-10-containing compounds, which selectively accumulate in tumor cells. When non-radioactive boron is irradiated with high energy neutrons, high-energy $\alpha$ particles and lithium nuclei are emitted, which leads to tumor cell death (63). This process possibly occurs via cell cycle arrest and apoptosis (64). Miyatake et al (65) investigated 22 cases of recurrent malignant glioma treated using BNCT. The results revealed that the post-OS time for all patients was 10.8 and 9.6 months for patients with glioblastoma. Pellettieri et al (20) reported a post-OS time of 8.7 months and a post-PFS time of 6 months in 12 recurrent cases of GBM, without the occurrence of severe acute toxicity. BNCT with bevacizumab was also found to benefit the survival of
4 recurrent $\mathrm{HGG}$ patients (66). BNCT selectively delivers a high radiation dose to the tumor, while limiting the toxicity to the surrounding normal tissues; this is a major advantage of the technique. In the future, further study is required to validate the role of BNCT in the treatment of recurrent high-grade glioma.

TM-601 is a synthetic peptide that binds to phosphatidyl inositide, a phosphorylated lipid on tumor cells (67). When TM-601 is labeled with ${ }^{131} \mathrm{I}$, it may suppress tumor growth. Mamelak et al (68) investigated the efficacy and safety of ${ }^{131} \mathrm{I}-\mathrm{TM}-601$ (labeled with $10 \mathrm{mCi}$ of ${ }^{131} \mathrm{I}$ ) for use in recurrent HGG patients who had previously received irradiation treatment. The post-OS times were was $25.7,77.6$ and 23.6 weeks for doses of $0.25,0.50$ and $1.00 \mathrm{mg}$, respectively. No grade 3 or 4 toxicities were reported. This alternative treatment may be delivered easily via venous injection. However, the study by Mamelak et al (68) was a phase I study, and thus, phase II studies are required.

\section{Conclusion}

A number of invasive and non-invasive re-irradiation techniques with proven efficacy are available for the treatment of recurrent HGG. Certain factors, including proximity to sensitive risk structures, KPS and tumor volume, must be considered comprehensively to improve individualized radiotherapy. If the tumor is large or located close to eloquent structures, FSRT should be selected to limit damage to the vital organs. For terminally ill patients, HFSRT may reduce treatment time, subsequently improving quality of life. With regard to smaller and unifocal tumors, SRS may be used for the precise delivery of high doses of radiation. For the application of BT, which is an invasive treatment, the KPS score should be considered and the refinement of treatment protocols may improve survival time. Furthermore, adjuvant treatment with agents such as bevacizumab and TMZ may increase treatment efficacy. In addition, novel treatment modalities have exhibited promising results. For example, PRDR presents a potential modality for patients with relatively large tumors. Furthermore, BNCT may selectively deliver radiation doses and ${ }^{131} \mathrm{I}-\mathrm{TM}-601$ may also deliver radiation that is highly localized to tumor sites. When indications are considered carefully, certain patient subgroups may benefit from re-irradiation for the treatment of recurrent HGG. However, curative treatments remain to be identified and thus, further study is urgently required.

\section{Acknowledgements}

This study was supported by the National Natural Science Foundation of China (grant no. 81201526) and the Shandong Province Natural Science Foundation (grant no. ZR2012HQ009).

\section{References}

1. Louis DN, Ohgaki H, Wiestler OD, Cavenee WK, Burger PC, Jouvet A, Scheithauer BW and Kleihues P: The 2007 WHO classification of tumours of the central nervous system. Acta Neuropathol 114: 97-109, 2007.

2. Wen PY and Kesari S: Malignant gliomas in adults. N Engl J Med 359: 492-507, 2008. 
3. Stupp R, Mason WP, van den Bent MJ, Weller M, Fisher B, Taphoorn MJ, Belanger K, Brandes AA, Marosi C, Bogdahn U, et al; European Organisation for Research and Treatment of Cancer Brain Tumor and Radiotherapy Groups; National Cancer Institute of Canada Clinical Trials Group: Radiotherapy plus concomitant and adjuvant temozolomide for glioblastoma. N Engl J Med 352: 987-996, 2005.

4. Bao S, Wu Q, McLendon RE, Hao Y, Shi Q, Hjelmeland AB, Dewhirst MW, Bigner DD and Rich JN: Glioma stem cells promote radioresistance by preferential activation of the DNA damage response. Nature 444: 756-760, 2006.

5. Bauman GS, Sneed PK, Wara WM, Stalpers LJ, Chang SM, McDermott MW, Gutin PH and Larson DA: Reirradiation of primary CNS tumors. Int J Radiat Oncol Biol Phys 36: 433-441, 1996.

6. Combs SE, Gutwein S, Thilmann Ch, Huber P, Debus J and Schulz-Ertner D: Stereotactically guided fractionated re-irradiation in recurrent glioblastoma multiforme. J Neurooncol 74 $167-171,2005$

7. Voynov G, Kaufman S, Hong T, Pinkerton A, Simon R and Dowsett R: Treatment of recurrent malignant gliomas with stereotactic intensity modulated radiation therapy. Am J Clin Oncol 25: 606-611, 2002.

8. Kim B, Soisson E, Duma C, Chen P, Hafer R, Cox C, Cubellis J, Minion A, Plunkett $M$ and Mackintosh R: Treatment of recurrent high grade gliomas with hypofractionated stereotactic image-guided helical tomotherapy. Clin Neurol Neurosurg 113 509-512, 2011

9. McKenzie JT, Guarnaschelli JN, Vagal AS, Warnick RE and Breneman JC: Hypofractionated stereotactic radiotherapy for unifocal and multifocal recurrence of malignant gliomas. J Neurooncol 113: 403-409, 2013.

10. Fokas E, Wacker U, Gross MW, Henzel M, Encheva E and Engenhart-Cabillic R: Hypofractionated stereotactic reirradiation of recurrent glioblastomas: A beneficial treatment option after high-dose radiotherapy? Strahlenther Onkol 185: 235-240, 2009.

11. Archavlis E, Tselis N, Birn G, Ulrich P, Baltas D and Zamboglou N: Survival analysis of HDR brachytherapy versus reoperation versus temozolomide alone: A retrospective cohort analysis of recurrent glioblastoma multiforme. BMJ Open 3 e002262, 2013

12. Combs SE, Gutwein S, Thilmann C, Debus J and Schulz-Ertner D: Reirradiation of recurrent WHO grade III astrocytomas using fractionated stereotactic radiotherapy (FSRT). Strahlenther Onkol 181: 768-773, 2005.

13. Vordermark D, Kölbl O, Ruprecht K, Vince GH, Bratengeier K and Flentje M: Hypofractionated stereotactic re-irradiation: Treatment option in recurrent malignant glioma. BMC Cancer 5 : $55,2005$.

14. Henke G, Paulsen F, Steinbach JP, Ganswindt U, Isijanov H, Kortmann RD, Bamberg M and Belka C: Hypofractionated reirradiation for recurrent malignant glioma. Strahlenther Onkol 185: 113-119, 2009

15. Elliott RE, Parker EC, Rush SC, Kalhorn SP, Moshel YA, Narayana A, Donahue B and Golfinos JG: Efficacy of gamma knife radiosurgery for small-volume recurrent malignant gliomas after initial radical resection. World Neurosurg 76: 128-140 discussion 61-62, 2011.

16. Cuneo KC, Vredenburgh JJ, Sampson JH, Reardon DA, Desjardins A, Peters KB, Friedman HS, Willett CG and Kirkpatrick JP: Safety and efficacy of stereotactic radiosurgery and adjuvant bevacizumab in patients with recurrent malignant gliomas. Int J Radiat Oncol Biol Phys 82: 2018-2024, 2012.

17. Larson DA, Suplica JM, Chang SM, Lamborn KR McDermott MW, Sneed PK, Prados MD, Wara WM, Nicholas MK and Berger MS: Permanent iodine 125 brachytherapy in patients with progressive or recurrent glioblastoma multiforme. Neuro Oncol 6: 119-126, 2004.

18. Darakchiev BJ, Albright RE, Breneman JC and Warnick RE Safety and efficacy of permanent iodine-125 seed implants and carmustine wafers in patients with recurrent glioblastoma multiforme. J Neurosurg 108: 236-242, 2008.

19. Cannon GM, Tomé WA, Robins HI and Howard SP: Pulsed reduced dose-rate radiotherapy: Case report: A novel re-treatment strategy in the management of recurrent glioblastoma multiforme. J Neurooncol 83: 307-311, 2007.

20. Pellettieri L, H-Stenstam B, Rezaei A, Giusti V and Sköld K An investigation of boron neutron capture therapy for recurrent glioblastoma multiforme. Acta Neurol Scand 117: 191-197, 2008
21. Cho KH, Hall WA, Gerbi BJ, Higgins PD, McGuire WA and Clark HB: Single dose versus fractionated stereotactic radiotherapy for recurrent high-grade gliomas. Int J Radiat Oncol Biol Phys 45: 1133-1141, 1999.

22. Combs SE, Thilmann C, Edler L, Debus J and Schulz-Ertner D Efficacy of fractionated stereotactic reirradiation in recurrent gliomas: Long-term results in 172 patients treated in a single institution. J Clin Oncol 23: 8863-8869, 2005.

23. Combs SE, Bischof M, Welzel T, Hof H, Oertel S, Debus J and Schulz-Ertner D: Radiochemotherapy with temozolomide as re-irradiation using high precision fractionated stereotactic radiotherapy (FSRT) in patients with recurrent gliomas. J Neurooncol 89: 205-210, 2008

24. Maier-Hauff K, Ulrich F, Nestler D, Niehoff H, Wust P, Thiesen B, Orawa H, Budach V and Jordan A: Efficacy and safety of intratumoral thermotherapy using magnetic iron-oxide nanoparticles combined with external beam radiotherapy on patients with recurrent glioblastoma multiforme. J Neurooncol 103: 317-324, 2011.

25. Minniti G, Armosini V, Salvati M, Lanzetta G, Caporello P, Mei M, Osti MF and Maurizi RE: Fractionated stereotactic reirradiation and concurrent temozolomide in patients with recurrent glioblastoma. J Neurooncol 103: 683-691, 2011.

26. Hundsberger T, Brügge D, Putora PM, Weder P, Weber J and Plasswilm L: Re-irradiation with and without bevacizumab as salvage therapy for recurrent or progressive high-grade gliomas. J Neurooncol 112: 133-139, 2013.

27. Flieger M, Ganswindt U, Schwarz SB, Kreth FW, Tonn JC, la Fougère C, Ertl L, Linn J, Herrlinger U, Belka C and Niyazi M: Re-irradiation and bevacizumab in recurrent high-grade glioma: An effective treatment option. J Neurooncol 117: 337-345, 2014.

28. Liem B J, Holland J M, Kang M Y, Hoffelt SC and Marquez CM: Karnofsky Performance Status assessment: Resident versus attending. J Cancer Educ 17: 138-141, 2002.

29. Chinot OL, Wick W and Cloughesy T: Bevacizumab for newly diagnosed glioblastoma. N Engl J Med 370: 2049, 2014.

30. Shepherd SF, Laing RW, Cosgrove VP, Warrington AP, Hines F, Ashley SE and Brada M: Hypofractionated stereotactic radiotherapy in the management of recurrent glioma. Int J Radiat Oncol Biol Phys 37: 393-398, 1997.

31. Grosu AL, Weber WA, Franz M, Stärk S, Piert M, Thamm R, Gumprecht H, Schwaiger M, Molls M and Nieder C: Reirradiation of recurrent high-grade gliomas using amino acid PET (SPECT)/CT/MRI image fusion to determine gross tumor volume for stereotactic fractionated radiotherapy. Int J Radiat Oncol Biol Phys 63: 511-519, 2005.

32. Ernst-Stecken A, Ganslandt O, Lambrecht U, Sauer R and Grabenbauer G: Survival and quality of life after hypofractionated stereotactic radiotherapy for recurrent malignant glioma. J Neurooncol 81: 287-294, 2007.

33. Gutin PH, Iwamoto FM, Beal K, Mohile NA, Karimi S, Hou BL, Lymberis S, Yamada Y, Chang J and Abrey LE: Safety and efficacy of bevacizumab with hypofractionated stereotactic irradiation for recurrent malignant gliomas. Int J Radiat Oncol Biol Phys 75: 156-163, 2009.

34. Patel M, Siddiqui F, Jin JY, Mikkelsen T, Rosenblum M, Movsas B and Ryu S: Salvage reirradiation for recurrent glioblastoma with radiosurgery: Radiographic response and improved survival. J Neurooncol 92: 185-191, 2009.

35. Fogh SE, Andrews DW, Glass J, Curran W, Glass C, Champ C, Evans JJ, Hyslop T, Pequignot E, Downes B, et al: Hypofractionated stereotactic radiation therapy: An effective therapy for recurrent high-grade gliomas. J Clin Oncol 28: 3048-3053, 2010.

36. Minniti G, Scaringi C, De Sanctis V, Lanzetta G, Falco T, Di Stefano D, Esposito V and Enrici RM: Hypofractionated stereotactic radiotherapy and continuous low-dose temozolomide in patients with recurrent or progressive malignant gliomas. J Neurooncol 111: 187-194, 2013

37. Shapiro LQ, Beal K, Goenka A, Karimi S, Iwamoto FM, Yamada Y, Zhang Z, Lassman AB, Abrey LE and Gutin PH: Patterns of failure after concurrent bevacizumab and hypofractionated stereotactic radiation therapy for recurrent high-grade glioma. Int J Radiat Oncol Biol Phys 85: 636-642, 2013.

38. Wuthrick EJ, Curran WJ Jr, Camphausen K, Lin A, Glass J, Evans J, Andrews DW, Axelrod R, Shi W, Werner-Wasik M, et al: A pilot study of hypofractionated stereotactic radiation therapy and sunitinib in previously irradiated patients with recurrent high-grade glioma. Int J Radiat Oncol Biol Phys 90: 369-375, 2014. 
39. Chalmers AJ, Ruff EM, Martindale C, Lovegrove N and Short SC: Cytotoxic effects of temozolomide and radiation are additive- and schedule-dependent. Int J Radiat Oncol Biol Phys 75: 1511-1519, 2009.

40. Den RB, Kamrava M, Sheng Z, Werner-Wasik M, Dougherty E, Marinucchi M, Lawrence YR, Hegarty S, Hyslop T, Andrews DW, et al: A phase I study of the combination of sorafenib with temozolomide and radiation therapy for the treatment of primary and recurrent high-grade gliomas. Int J Radiat Oncol Biol Phys 85 321-328, 2013.

41. Shrieve DC, Alexander E III, Wen PY, Fine HA, Kooy HM, Black PM and Loeffler JS: Comparison of stereotactic radiosurgery and brachytherapy in the treatment of recurrent glioblastoma multiforme. Neurosurgery 36: 275-284, 1995.

42. Hall WA, Djalilian HR, Sperduto PW, Cho KH, Gerbi BJ, Gibbons JP, Rohr M and Clark HB: Stereotactic radiosurgery for recurrent malignant gliomas. J Clin Oncol 13: 1642-1648, 1995.

43. Combs SE, Widmer V, Thilmann C, Hof H, Debus J and Schulz-Ertner D: Stereotactic radiosurgery (SRS): Treatment option for recurrent glioblastoma multiforme (GBM). Cancer 104 2168-2173, 2005

44. Maranzano E, Anselmo P, Casale M, Trippa F, Carletti S, Principi M, Loreti F, Italiani M and Caserta C: Treatment of recurrent glioblastoma with stereotactic radiotherapy: Long-term results of a mono-institutional trial. Tumori 97: 56-61, 2011.

45. Torok JA, Wegner RE, Mintz AH, Heron DE and Burton SA Re-irradiation with radiosurgery for recurrent glioblastoma multiforme. Technol Cancer Res Treat 10: 253-258, 2011.

46. Conti A, Pontoriero A, Arpa D, Siragusa C, Tomasello C, Romanelli P, Cardali S, Granata F, De Renzis C and Tomasello F: Efficacy and toxicity of CyberKnife re-irradiation and 'dose dense' temozolomide for recurrent gliomas. Acta Neurochir (Wien) 154: 203-209, 2012

47. Skeie BS, Enger PØ, Brøgger J, Ganz JC, Thorsen F, Heggdal JI and Pedersen PH: $\gamma$ knife surgery versus reoperation for recurrent glioblastoma multiforme. World Neurosurg 78: 658-669, 2012.

48. Cabrera AR, Cuneo KC, Desjardins A, Sampson JH, McSherry F, Herndon JE II, Peters KB, Allen K, Hoang JK, Chang Z, et al: Concurrent stereotactic radiosurgery and bevacizumab in recurrent malignant gliomas: A prospective trial. Int J Radiat Oncol Biol Phys 86: 873-879, 2013.

49. Martínez-Carrillo M, Tovar-Martín I, Zurita-Herrera M Del Moral-Ávila R, Guerrero-Tejada R, Saura-Rojas E Osorio-Ceballos JL, Arrebola-Moreno JP and Expósito-Hernández J: Salvage radiosurgery for selected patients with recurrent malignant gliomas. Biomed Res Int 2014: 657953 , 2014.

50. Mayer R and Sminia P: Reirradiation tolerance of the human brain. Int J Radiat Oncol Biol Phys 70: 1350-1360, 2008.

51. Simon JM, Cornu P, Boisserie G, Hasboun D, Tep B, Hardiman C, Valery CA, Delattre JY, Dormont D, Baillet F and Mazeron JJ: Brachytherapy of glioblastoma recurring in previously irradiated territory: Predictive value of tumor volume. Int J Radiat Oncol Biol Phys 53: 67-74, 2002.

52. Barani IJ and Larson DA: Radiation therapy of glioblastoma. Cancer Treat Res 163: 49-73, 2015.

53. Tatter SB, Shaw EG, Rosenblum ML, Karvelis KC, Kleinberg L, Weingart J, Olson JJ, Crocker IR, Brem S, Pearlman JL, et al: An inflatable balloon catheter and liquid 125I radiation source (GliaSite Radiation Therapy System) for treatment of recurrent malignant glioma: Multicenter safety and feasibility trial. J Neurosurg 99: 297-303, 2003.
54. Chan TA, Weingart JD, Parisi M,Hughes MA, Olivi A, Borzillary S, Alahakone D, Detorie NA, Wharam MD and Kleinberg L: Treatment of recurrent glioblastoma multiforme with GliaSite brachytherapy. Int J Radiat Oncol Biol Phys 62: 1133-1139, 2005.

55. Gabayan AJ, Green SB, Sanan A, Jenrette J, Schultz C, Papagikos M, Tatter SP, Patel A, Amin P, Lustig R, et al: GliaSite brachytherapy for treatment of recurrent malignant gliomas: A retrospective multi-institutional analysis. Neurosurgery 58: 701-709, 2006.

56. Tselis N, Kolotas C, Birn G, Röddiger S, Filipowicz I, Kontova M, Fountzilas G, Selviaridis P, Baltas D, Heyd R, et al: CT-guided interstitial HDR brachytherapy for recurrent glioblastoma multiforme. Long-term results. Strahlenther Onkol 183: 563-570, 2007.

57. Fabrini MG, Perrone F, De Franco L, Pasqualetti F, Grespi S, Vannozzi $\mathrm{R}$ and Cionini L: Perioperative high-dose-rate brachytherapy in the treatment of recurrent malignant gliomas. Strahlenther Onkol 185: 524-529, 2009.

58. Kickingereder P, Hamisch C, Suchorska B, Galldiks N, Visser-Vandewalle V, Goldbrunner R, Kocher M, Treuer H, Voges J and Ruge MI: Low-dose rate stereotactic iodine-125 brachytherapy for the treatment of inoperable primary and recurrent glioblastoma: Single-center experience with 201 cases. J Neurooncol 120: 615-623, 2014.

59. Gregg EC, Yau TM and Kim SC: Effect of low dose rate radiation on cell growth kinetics. Biophys J 28: 81-91, 1979.

60. Koot RW, Maarouf M, Hulshof MC, Voges J, Treuer H, Koedooder C, Sturm V and Bosch DA: Brachytherapy: Results of two different therapy strategies for patients with primary glioblastoma multiforme. Cancer 88: 2796-2802, 2000.

61. Archavlis E, Tselis N, Birn G, Ulrich P and Zamboglou N: Salvage therapy for recurrent glioblastoma multiforme: A multimodal approach combining fluorescence-guided resurgery, interstitial irradiation and chemotherapy. Neurol Res 36: 1047-1055, 2014.

62. Adkison JB, Tomé W, Seo S, Richards GM, Robins HI, Rassmussen K, Welsh JS, Mahler PA and Howard SP: Reirradiation of large-volume recurrent glioma with pulsed reduced-dose-rate radiotherapy. Int J Radiat Oncol Biol Phys 79: 835-841, 2011.

63. Mishima Y, Honda C, Ichihashi M, Obara H, Hiratsuka J, Fukuda H, Karashima H, Kobayashi T, Kanda K and Yoshino K: Treatment of malignant melanoma by single thermal neutron capture therapy with melanoma-seeking 10B-compound. Lancet 2: 388-389, 1989.

64. Sun T, Zhang Z, Li B, Chen G, Xie X, Wei Y, Wu J, Zhou Y and Du Z: Boron neutron capture therapy induces cell cycle arrest and cell apoptosis of glioma stem/progenitor cells in vitro. Radiat Oncol 8: 195, 2013

65. Miyatake S, Kawabata S, Yokoyama K, Kuroiwa T, Michiue H, Sakurai Y, Kumada H, Suzuki M, Maruhashi A, Kirihata M and Onoc K: Survival benefit of boron neutron capture therapy for recurrent malignant gliomas. Appl Radiat Isot 67 (7-8 Suppl): S22-S24, 2009.

66. Miyatake S, Kawabata S, Hiramatsu R, Furuse M, Kuroiwa T and Suzuki M: Boron neutron capture therapy with bevacizumab may prolong the survival of recurrent malignant glioma patients: Four cases. Radiat Oncol 9: 6, 2014.

67. DeBin JA, Maggio JE and Strichartz GR: Purification and characterization of chlorotoxin, a chloride channel ligand from the venom of the scorpion. Am J Physiol 264: C361-C369, 1993.

68. Mamelak AN, Rosenfeld S, Bucholz R, Raubitschek A, Nabors LB, Fiveash JB, Shen S, Khazaeli MB, Colcher D, Liu A, et al: Phase I single-dose study of intracavitary-administered iodine-131-TM-601 in adults with recurrent high-grade glioma. J Clin Oncol 24: 3644-3650, 2006. 